IZA DP No. 5544

Age Biased Technical and Organisational Change, Training and Employment Prospects of Older Workers

Luc Behaghel

Eve Caroli

Muriel Roger

March 2011 


\title{
Age Biased Technical and Organisational Change, Training and Employment Prospects of Older Workers
}

\author{
Luc Behaghel \\ Paris School of Economics (INRA) and CREST \\ Eve Caroli \\ Paris Ouest University - EconomiX, \\ Paris School of Economics and IZA \\ Muriel Roger \\ Paris School of Economics (INRA) and INSEE
}

\author{
Discussion Paper No. 5544 \\ March 2011
}

IZA

P.O. Box 7240

53072 Bonn

Germany

Phone: +49-228-3894-0

Fax: +49-228-3894-180

E-mail: iza@iza.org

Any opinions expressed here are those of the author(s) and not those of IZA. Research published in this series may include views on policy, but the institute itself takes no institutional policy positions.

The Institute for the Study of Labor (IZA) in Bonn is a local and virtual international research center and a place of communication between science, politics and business. IZA is an independent nonprofit organization supported by Deutsche Post Foundation. The center is associated with the University of Bonn and offers a stimulating research environment through its international network, workshops and conferences, data service, project support, research visits and doctoral program. IZA engages in (i) original and internationally competitive research in all fields of labor economics, (ii) development of policy concepts, and (iii) dissemination of research results and concepts to the interested public.

IZA Discussion Papers often represent preliminary work and are circulated to encourage discussion. Citation of such a paper should account for its provisional character. A revised version may be available directly from the author. 


\title{
ABSTRACT \\ Age Biased Technical and Organisational Change, Training and Employment Prospects of Older Workers
}

\begin{abstract}
We analyse the role of training in mitigating the negative impact of technical and organizational changes on the employment prospects of older workers. Using a panel of French firms in the late 1990s, we first estimate wage bill share equations for different age groups. Consistently with what is found in the literature, we find that adopting new technologies and innovative work practices negatively affects the wage bill share of older workers. In contrast, training older workers more than average increases their share in the wage bill in the next period. So, training contributes to offset the negative impact of ICT and innovative work practices. However, it does not reduce the age bias associated with these innovative devices: the interaction terms between training and ICT/innovative work practices are either insignificant or negative. As a second step, we estimate the impact of ICT, innovative work practices and training on employment flows by age group in the next period. We get similar results to those obtained with wage bill shares. Overall, training appears to have a positive impact on the employability of older workers, but it offers limited prospects to dampen the age bias associated with new technologies and innovative work practices.
\end{abstract}

JEL Classification: J14, J24, J26, O30

Keywords: technical change, organizational change, training, older workers

Corresponding author:

Eve Caroli

Paris School of Economics

48 boulevard Jourdan

75014 Paris

France

E-mail: caroli@pse.ens.fr

\footnotetext{
* We are grateful to Hélène Garner, Dominique Goux, Céline Thévenot, Serge Volkoff and all members of the DARES "Gestion des Ages" stirring committee for helpful comments and suggestions. We gratefully acknowledge financial support from DARES (Gestion des Ages program) and from the French research agency (Agence Nationale de la Recherche) - Grant $n^{\circ}$ ANR-08-JCJC-0067-01.
} 


\section{Introduction}

In most European countries, population has been ageing quickly in recent years and this trend is not expected to revert in the near future. A direct consequence of this has been the increase in the ratio of retirees to working population, which has generated in turn growing budget unbalances in the pension systems. In order to reduce the resulting deficits, many governments have increased the legal age of retirement, hoping that this would decrease the retiree-to-working-population ratio. The success of such policy crucially depends of course on whether older workers are able to find a job or at least stay in employment (see Boldrin et al, 1999). So, it raises the issue of the demand for labour addressed by firms to older workers.

There is evidence in the literature that the demand for older workers has been negatively affected by the rapid development of information and communication technologies (ICT) and of innovative work practices in the past decades (see Aubert et al, 2006, Beckmann, 2007 and Ronningen, 2007). Underlying this process is the fact that ICT accelerate skill obsolescence. Given that older workers have completed their education less recently than younger ones, they are more affected by the loss of competence. In this context, continuous training becomes a key policy instrument to foster the employability of older workers. The question we tackle in this paper is: how efficient is continuous training in improving the employment prospects of older workers in an environment characterised by the development of new technologies and innovative work practices?

In order to answer this question, we first estimate wage bill share equations for different age groups. In order to control for unobserved heterogeneity and potential reverse causality we estimate long difference equations in which the change in the wage bill share of each age group is a function of the change in ICT and innovative work practices lagged one period and the change in training lagged one period. Consistently with what is found in the literature, we find that adopting new technologies and innovative work practices negatively affects the wage bill share of older workers. In contrast, training older workers more than average increases their share in the wage bill in the next period. So, training contributes to offset the negative impact of ICT and innovative work practices. However, it does not reduce the age bias associated with these innovative devices: the interaction terms between training and ICT/innovative work practices are either insignificant or negative. As a second step, we estimate the impact of ICT, innovative work practices and training on employment flows by age group in the next period. We get similar results to those obtained with wage bill shares. 
Innovative devices negatively affect older workers with respect to other age groups either because they increase hirings in a smaller proportion or because they raise separations more than average. In contrast, training protects older workers by reducing their turnover or by increasing hirings more than for other age groups. Overall, training appears to have a positive impact on the employability of older workers, but it offers limited prospects to dampen the age bias associated with new technologies and innovative work practices.

Our paper contributes to the now vast literature on age biased technical change. The idea that technological and organisational changes negatively affect older workers has been tested in various ways in the literature. A first strand of papers investigates whether age has a negative impact on computer use. On UK data, Borghans and Ter Weel (2002) find no evidence of such phenomenon. In contrast, Friedberg (2003) finds partial evidence of skills obsolescence in the USA, with technological change in a worker's environment having a negative impact on computer use, but only for workers close to retirement. For Germany, Schleife (2006) finds a strong and negative correlation between workers' age and computer use. Similar results are found for the Netherlands by Koning and Gelderblom (2006). However, these studies are flawed by selection bias. If workers who are less able to adapt to new technologies and innovative work practices have already retired or been laid-off, the effect of age will be underestimated when looking at how it correlates with computer use. A second empirical strategy has therefore consisted in estimating the impact of computer use on retirement decisions. On U.S. data, Bartel and Sicherman (1993) show that workers in industries with a higher rate of technological change tend to retire later. However, unexpected changes in the rate of technological change induce workers to retire earlier. Similar results are obtained by Haegeland et al (2007) for Norway. A last strand of papers have taken a different view and investigated the impact of the introduction of ICT and innovative work practices on firm's labour demand for older workers (Aubert et al, 2006, Beckmann, 2007, Ronningen, 2007). They all find that the introduction of innovative devices negatively affects the wage bill share of older workers. Our paper uses the same methodology. We also find evidence of age biased technical and organisational change and extend the analysis to consider the potential role of training in this adjustment.

Our work also contributes to the literature on the impact of training on the employability of older workers. Not much has been done so far on this issue. Using subjective data on job security, Bassanini (2006) provides evidence that training taken with the previous employer has a positive impact on the perceived job security of older workers. Schleife (2008) uses a 
more objective measure of employability and shows that the proportion of older workers receiving IT training is positively correlated with their share in employment three years later. The question we ask in this paper is: is this effect of training strong enough to dampen the age bias associated with the introduction of ICT and innovative work practices? For Germany, Schleife (2008) finds that the positive correlation between IT training provided to older workers and their share in employment is strongest in IT-intensive industries whereas it is insignificant in less IT-intensive ones. Song (2009) suggests that training could actually harm older workers in a context of rapid development of ICT if it is firm specific. On CPS data, he finds that the probability of displacement by position abolition increases with age, ICT use within an occupation/industry and with the provision of specific training by the employer. Based on these results, he conjectures that firm specific training may undermine job security of older workers in a context of rapid technological changes. The reason for this would be that technological change depreciates the existing stock of firm-specific human capital thus leading firms to dismiss workers because they find it unprofitable to retrain them. We test whether the employment prospects of older workers are better or worse when the introduction of innovative devices is combined with training. We find that although training improves the share of older workers in employment and reduces their turnover it is not strong enough to dampen the age bias associated with ICT and innovative work practices.

The layout of the rest of the paper is as follows. Section 1 presents the econometric model. Section 2 describes the data. Section 3 reports results and Section 4 concludes.

\section{The econometric model}

In order to study the relationships between training and the wage bill shares of the various age groups in innovative firms, we use a classical labour demand framework. As is standard in the literature, we assume that the cost function is a restricted translog (see for example Caroli and Van Reenen, 2001).

\subsection{Wage bill shares}

Since we are interested in the joint effects of training and innovation on the age structure of the workforce, we assume that the only variable factors are the different types of labour as characterised by their age and indexed by $a$. Correspondingly, we assume that capital is a "quasi-fixed" factor which varies only in the long run and can therefore be considered as exogenous in the short run. 
Under these assumptions, the wage bill shares of the various age groups are as follows - see Aubert et al (2006):

$$
\begin{aligned}
& S_{a, i, t}=\alpha_{a}+\sum_{a^{\prime} \in\{1 \ldots A\}} \gamma_{a, a^{\prime}} \ln \left(W_{a^{\prime}}\right)_{i t}+\gamma_{a, K} \ln (K)_{i t}+\gamma_{a, T E C H} \cdot \ln (T E C H)_{i t}+\gamma_{a, H K} \cdot \ln (H K)_{i t} \\
& +\gamma_{a, V A} \ln (V A)_{i t}+\gamma_{a, Z} \cdot Z_{i t}+\varepsilon_{a, i, t}
\end{aligned}
$$

where $S_{a, i, t}$ denotes the wage bill share of age group $a$ in firm $i$ at date $t, K$ the stock of physical capital, $V A$ the value-added of the firm, $W_{a^{\prime}}$ the hourly wage of age group $a^{\prime}, Z$ a vector of industry and size dummies, and $\varepsilon_{a, i}$ an error term. We assume that the stock of capital of the firm also encompasses technological capital (TECH) and human capital $(H K)$. TECH captures the use of information and communication technologies and/or innovative work practices and $H K$ captures the stock of human capital - potentially specific to each age group - used in the production process. The total number of age groups is $A$.

Since we consider the system of wage bill share equations for all age groups, we need to place additional restrictions on the parameters in order to make sure that all shares sum up to 1. Symmetry implies that:

$$
\gamma_{a, a^{\prime}}=\gamma_{a^{\prime}, a}
$$

and homogeneity implies that:

$$
\sum_{a=1}^{A} \alpha_{a}=1 \text { and } \sum_{a=1}^{A} \gamma_{a, u}=0 \forall u \in U=\{u=1, \ldots, A ; V A ; K ; T E C H ; H K ; Z\}
$$

Given that wage bill shares of the various age groups sum up to 1 , one of the equations becomes redundant. So, we estimate the system for all age categories $a$ but the first one. The model becomes:

$$
\begin{aligned}
& S_{a, i, t}=\alpha_{a}+\sum_{a \in\{2 \ldots A\}} \gamma_{a, a^{\prime}} \ln \left(W_{a^{\prime}} / W_{1}\right)_{i t}+\gamma_{a, K} \ln (K)_{i t}+\gamma_{a, T E C H} \ln (T E C H)_{i t}+\gamma_{a, H K} \cdot \ln (H K)_{i t} \\
& +\gamma_{a, V A} \ln (V A)_{i t}+\gamma_{a, Z} \cdot Z_{i t}+\varepsilon_{a, i, t} \quad \forall a \in\{2 \ldots A\}
\end{aligned}
$$

The youngest age group (indexed by 1) is taken as the reference in order to compute relative wages $\ln \left(W_{a^{\prime}} / W_{1}\right)_{i}$ and is therefore eliminated from the equation system. This age group corresponds to workers aged 20 to 29 years old (see the data section).

A first problem raised by equations (2) is that of reverse causality. The correlation we 
estimate may indeed capture the impact of the age structure of the workforce on training rather than the opposite. This problem arises in particular if the age structure is persistent over time which is likely to be the case. ${ }^{1}$ In order to overcome this problem, we estimate our model in long differences where past training (i.e. the change in the stock of human capital between $t-1$ and $t$ ) and innovation (i.e. the change in the stock of technological and organisational capital) affect the subsequent change in the age structure of the workforce (between $t$ and $t+1$ ), controlling for its initial value. ${ }^{2}$ This yields our estimated specification:

$$
\begin{aligned}
& \Delta S_{a, i, t+1}=\sum_{a^{\prime} \in\{2 \ldots A\}} \gamma_{a, a^{\prime}} \Delta \ln \left(W_{a^{\prime}} / W_{1}\right)_{i t}+\gamma_{a, K} \Delta \ln (K)_{i t}+\gamma_{a, I N N O V}{I N N O V_{i t}+\gamma_{a, T R A I N} \cdot \operatorname{TRAIN}_{i t}} \\
& +\gamma_{a, V A} \Delta \ln (V A)_{i t}+\sum_{a^{\prime} \in\{1 \ldots A\}} \zeta_{a^{\prime}} P_{a^{\prime}, i, t-1}+\gamma_{a, X} . X_{a, i, t}+\varepsilon_{a, i, t} \quad \forall a \in\{2 \ldots A\}
\end{aligned}
$$

where $\Delta S_{a, i, t+1}$ is the change in the wage bill share of the various age groups, $\Delta \ln (K)_{i t}$ the change in the $\log$ of the physical capital stock, $\Delta \ln (V A)_{i t}$ the change in the log of valueadded, $\Delta \ln \left(W_{a^{\prime}} / W_{1}\right)_{i t}$ the change in relative wages. $P_{a, i, t-1}$ is the age structure of the workforce before the introduction of ICT and innovative work practices ${ }^{3}$ and $X_{i t}$ is a vector of controls including size and industry dummies. INNOV $V_{i t}$ captures the introduction of information and communication technologies and/or innovative work practices and is a proxy of $\Delta \ln (T E C H)$. Similarly, the change in the stock of human capital $\Delta \ln (K H)$ is proxied by continuous training $\left(\operatorname{TRAIN}_{i t}\right)$. Firms' investments in training are indeed a flow which increments the stock of human capital. ${ }^{4}$

This specification aims at studying the impact of training investments - which may be specific to the various age groups - on the employment prospects of older workers and the

\footnotetext{
${ }^{1}$ In order to highlight this point, let's consider the extreme case in which there is no entry nor exit between the end of the 1980s and 1998 (the year that we consider - see below). The age structure of the workforce in 1998 would then be identical to that of 1988 with every employee being 10 years older. The theory of human capital accumulation over the life cycle (Ben Porath, 1967) as well as empirical evidence suggest that middle-aged workers receive a disproportionate amount of training. So, firms in which a large proportion of employees is aged 30 to 50 years old in 1988 will massively invest in training and will mechanically have a workforce aged 40 to 60 years old in 1998. This would result in a positive correlation between training in 1988 and the proportion of workers aged 40 to 60 in the workforce in 1998. But this correlation would not be due to the causal effect of training on maintaining senior workers in employment.

${ }^{2}$ A potential drawback of this method is that if new ICT or innovative work practices have been introduced (between $t$ and $t+1$ ), they do not show up in our data which may lead us to consider as non innovative firms that will become so a few years later. Note however that this should bias our results towards finding no impact of new ICT and innovative work practices.

${ }^{3}$ More specifically, it is the share of the various age groups in the number of days worked as of 1994.

${ }^{4}$ We introduce time subscripts $t, t+1$ and $t-1$ to make clear that variables are measured over different periods. However, the introduction of ICT and innovative work practices is only observed over one period; each firm enters the estimation only once (with some variables in 3-year difference).
} 
role the former may play in mitigating the effects of innovation. Clearly, even though reverse causality problems are taken into account and several confounding factors are controlled for, a causal interpretation of the estimates still relies upon the arguably strong assumption that training and innovations are exogenous to future changes in the structure of the workforce. This assumption is common in the literature on technical and organizational change, given the lack of plausible instruments. It must however be kept in mind.

In our data, the introduction of ICT and/or innovative work practices $\left(I N N O V_{i t}\right)$ is measured between the beginning of 1995 and the end of 1997. In order to mitigate the reverse causality issue, we consider changes in the wage bill shares of the various age groups $\left(\Delta S_{a, i, t+1}\right)$ over 1998-2000. Our training measure is averaged over 1995-1997 and we control for the age structure of the workforce as of 1994, i.e. before the introduction of any innovative device.

A problem with equations (3) is that the errors terms $\varepsilon_{a, i}$ may be correlated across age groups within a given firm. So, in order to get an efficient estimator of the standard errors of the various coefficients, we need to take into account the shape of the variance-covariance matrix $\varepsilon_{i}=\left\{\varepsilon_{2, i}, \ldots, \varepsilon_{A, i}\right\}$. We do this by estimating a SUR model by joint generalised least squares (JGLS). When the explanatory variables are the same in all equations - as is the case here this amounts to estimating the system by OLS equation by equation. ${ }^{5}$

\subsection{Workers' flows}

Another way to get at the role of innovation and training in shaping the employment prospects of older workers is to estimate directly workers' flows both into and out of firms as a function of past adoption of ICT and/or innovative work practices and past training investments. This allows us to identify the mechanisms through which innovation and training affect labour demand: is the main effect on hirings or alternatively on separations?

We denote $N_{a, i, t}^{H I R E}$ the number of workers aged $a$ who are hired at year $t$ in firm $i$ and $N_{a, i, t}^{E X I T}$ the number of workers of the same age group who leave the firm in the course of the year.

We define the share of newly hired workers aged $a$ in firm $i$ at date $t$ as $P_{a, i, t}^{\text {HIRE }}=\frac{N_{a, i, t}^{\text {HIRE }}}{N_{a, i, t}}$ and

\footnotetext{
${ }^{5}$ See, e.g., Theorem 7.6 in Wooldridge, 2002.
} 
the share of workers leaving the firm as: $P_{a, i, t}^{E X I T}=\frac{N_{a, i, t}^{E X I T}}{N_{a, i, t}}$. These shares are averaged over the period 1998-2000. We assume that $P_{a, i, t}^{H I R E}$ and $P_{a, i, t}^{\text {EXIT }}$ can be written as:

$$
\begin{gathered}
P_{a, i, t}^{\text {HIRE }}=\alpha_{a}^{H I R E}+\beta_{a, I N N O V}^{\text {HIRE }} \operatorname{INNOV}_{i, t-1}+\beta_{a, T R A I N}^{\text {HIRE }} \operatorname{TRAIN}_{i, t-1}+\beta_{a, K}^{H I R E} \Delta \ln (K)_{i, t} \\
+\beta_{a, V A}^{H I R E} \Delta \ln (V A)_{i, t}+\sum_{a \in\{2 \ldots A\}} \beta_{a, a^{\prime}}^{\text {HIRE }} \Delta \ln \left(W_{a} / W_{1}\right)_{i, t}+\sum_{a \in\{2 \ldots A\}} \beta_{a}^{\text {HIRE }} \cdot P_{a, i, t-1}+\beta_{a, M}^{\text {HIRE }} \cdot M_{a, i, t}+\varepsilon_{a, i, t}^{H I R E}
\end{gathered}
$$

and

$$
\begin{aligned}
& P_{a, i, t}^{E X I T}=\alpha_{a}^{E X I T}+\beta_{a, I N N O V}^{E X I T} I N N O V_{i, t-1}+\beta_{a, T R A I N}^{E X X T} \operatorname{TRAIN}_{i, t-1}+\beta_{a, K}^{E X I T} \Delta \ln (K)_{i, t} \\
& +\beta_{a, V A}^{E X I T} \Delta \ln (V A)_{i, t}+\sum_{a \in\{2 \ldots A\}} \beta_{a, a^{\prime}}^{E X I T} \Delta \ln \left(W_{a} / W_{1}\right)_{i, t}+\sum_{a \in\{2 \ldots A\}} \beta_{a}^{E X I T} \cdot P_{a, i, t-1}+\beta_{a, M}^{E X I T} \cdot M_{a, i, t}+\varepsilon_{a, i, t}^{E X I T}
\end{aligned}
$$

$I N N O V_{i, t-1}$ denotes our measure of innovation and $\operatorname{TRAIN}_{i, t-1}$, the investment in training which are both measured over 1995-1997. $\left\{\Delta \ln \left(W_{a} / W_{1}\right)_{i, t} ; \Delta \ln (K)_{i, t} ; \Delta \ln (V A)_{i, t}\right\}$ is a vector of demand factors (change in relative wages, in physical capital and in value-added between 1998 and 2000) specific to firm $i . P_{a, i, t-1}$ is the share of age group $a$ in the workforce before the introduction of innovation (i.e. as of 1994) and $M_{i t}$ is a vector of controls identical to $X_{i t}$ in equation (3) but including year fixed effects for 1999 and 2000. $\varepsilon_{a, i, t-1}^{H I R E}$ and $\varepsilon_{a, i, t-1}^{E X I T}$ are stochastic error terms.

The main advantage of this linear model is that it allows us to estimate the share of inflows and outflows for all age groups simultaneously by using the SUR method - see section 2.1 above. In turn, this allows us to take into account the potential correlation between hirings and separations across various age groups.

Given that we are interested in the impact of innovation and training upon hirings and separations of older workers relative to younger ones, we decompose $\beta_{a, I N N O V}^{\text {HIRE }}$ and $\beta_{a, T R A I N}^{\text {HIRE }}$ (resp. $\beta_{a, I N N O V}^{E X I T}$ and $\beta_{a, T R A I N}^{\text {EXIT }}$ ) into two different terms: $\theta^{\text {HIRE }}$ (resp. $\theta^{\text {EXIT }}$ ) is a component that is common to all age groups and represents the average impact of innovation or training on hiring (resp. on separations) and $\theta_{a}^{H I R E}$ (resp. $\theta_{a}^{E X I T}$ ) is a component which is age specific: 


$$
\beta_{a}^{H I R E}=\theta^{H I R E}+\theta_{a}^{H I R E} \text { and } \beta_{a}^{E X I T}=\theta^{E X I T}+\theta_{a}^{E X I T}
$$

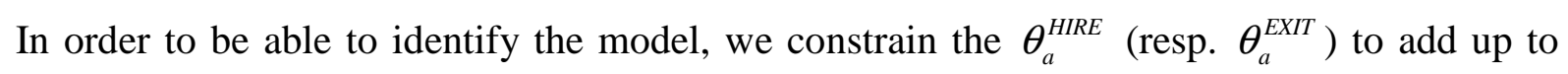
zero. As a consequence:

$$
\theta^{H I R E}=\frac{\sum \beta_{a}{ }^{H I R E}}{A} \text { et } \theta_{a}^{\text {HIRE }}=\beta_{a}^{\text {HIRE }}-\frac{\sum \beta_{a}^{\text {HIRE }}}{A}
$$

The same holds for separations.

\section{The data}

The data that we use come from several sources. Information on ICT and innovative work practices comes from the COI survey (Changements Organisationnels et Informatisation) carried out by $\operatorname{SESSI}^{6}$ at the end of 1997 and covering 4,283 firms with more than 20 workers in the manufacturing sector. ${ }^{7}$ In order to get information on wages and on the age structure of the workforce, we matched COI with mandatory social security reports: the DADS files (Déclarations Annuelles des Données Sociales). The DADS is an exhaustive dataset providing information on firm size and industry on a yearly basis since 1994. Moreover, for each employee, the DADS has information on the number of hours and days worked during the year, as well as on wages, age and occupation. Information on physical capital and valueadded comes from the BRN (Bénéfices Réels et Normaux) which consists of firms' balance sheets collected by the tax administration. It contains more than 600,000 firms from the private non-financial sector and covers about $80 \%$ of total sales in the economy.

Training data are retrieved from the "24-83" fiscal records. They contain information on the number of workers receiving training and the volume of training hours broken down by gender, age and occupation for every year. The "24-83" records are exhaustive for all French firms with more than 10 employees, but only a sample is available for research. This sample contains 15 to 20,000 firms every year but a larger sample (30 to 40,000 firms) is available every three years.

Matching the different databases leaves us with a sample of 2,352 firms as compared to 4,283 in the original COI dataset. This is due to the fact that we only keep those firms for which we have data on training while the "24-83" records are not exhaustive. The firms that we lose are

\footnotetext{
${ }^{6}$ French Ministry of Industry.

${ }^{7}$ Complementary surveys have been conducted in the food-processing, trade and service sectors, but the number of firms covered by each of them is much smaller than in the manufacturing sector (resp. 970, 648 and 1482). Moreover, the questions asked being somewhat different, we will focus exclusively on the manufacturing sector.
} 
essentially small ones since the first decile of the size distribution has less than 26 workers in the original dataset as compared to 34 in ours. Similarly, the median size of firms in our sample is 150 workers as compared to 86 in the COI database and the average size is 552 as compared to 429 in COI. Nonetheless, the distribution of firms across industries is very similar in both datasets: about half of the firms belong to the intermediate good sector $48.1 \%$ in our sample as compared to $45.2 \%$ in COI (see Appendix Table A.1) - and almost one fourth is in the durable good sector $-23.6 \%$ dans COI as compared to $23.4 \%$ in our sample. The only notable difference lies in the share of firms in the motor vehicle manufacturing industry - with $4.6 \%$ in our sample as compared to $3.7 \%$ in $\mathrm{COI}-$ and to a smaller extent in the non-durable good sector $-21.3 \%$ in our database as compared to $25.1 \%$ in COI. But overall, differences between both datasets remain very limited.

As regards workers' flows, we allow adjustment to take time and thus pool our data over 1998-2000. We jointly estimate employment flows for all groups in each firm. So we use a sample of 6,824 firms * year; for each of these, we measure inflows and outflows by age groups.

The age groups that we consider are 20 to 29,30 to 39,40 to 49 and 50 to 59 years old. Employees aged 60 and more are excluded given that the legal age of retirement was 60 during the period under study.

Using the information available in the COI dataset, we define 4 indicators of introduction of new technologies and innovative work practices. Following Biscourp et al. (2002), our first indicator is Internet which takes value 1 if the firm uses this technology either for emailing or to diffuse or gather information; it takes value 0 otherwise. We assume that Internet being at its very start in France in the mid-1990s, the rate of use declared in 1997 is equivalent to an adoption rate. Our second indicator is D_COMP, which captures the introduction of networkinterconnected computers in the production department. D_COMP is equal to 1 if the firm has introduced this type of equipment between 1994 and 1997; 0 otherwise. The COI survey also has information on the introduction of innovative work practices. A first indicator captures the reduction in hierarchical layers within firms: D_HIERAR is equal to 1 if the number of hierarchical layers was smaller in 1997 than in 1994; 0 otherwise. A second indicator captures the increase in the amount of responsibility awarded to operators over the period: D_RESP varies between -10 and +10 according to the number of new responsibilities 
operators have been awarded between 1994 and $1997^{8}$.

As regards training, the "24-83" records provide information on the relative access rate to training for three different age groups: younger than 25 years old, 25 to 44 years old and 45 and older. More precisely, for each of the above age groups, we build a variable denoted TRAIN_X which is equal to the rate of training in age group $\mathrm{X}$ divided by the average rate of training in the workforce. ${ }^{9}$ This variable captures the relative rate of training across the various age groups. ${ }^{10}$ For the sake of coherence with our technical and organisational change indicators, this variable is averaged over 1995-1997. Descriptive statistics are provided in Appendix Tables A2 to A5.

\section{Results}

\subsection{Change in the age structure of the workforce, innovation and training}

As a first step, we estimate the impact of the adoption of ICT and innovative work practices on the subsequent change in the age structure of the workforce, controlling for the initial age structure to the extent that it generates a mechanical change in the wage bill shares of the various age groups (see Table 1). Our results are similar to those in Aubert et al. (2006). ICT and innovative work practices appear to be age biased: the introduction of the Internet is correlated to an increase in the share of workers aged 30-39 in the wage bill, whereas it is associated with a decrease in the share of workers aged 50-59. By contrast, the adoption of network-interconnected computers does not seem to affect the age structure of the workforce, at least at this level of aggregation. The introduction of innovative work practices also affects the wage bill share of the various age groups. Like the Internet, the increase in the amount of responsibility awarded to operators is associated with an increase in the share of young workers (30 to 39) in the wage bill and with a reduction in the share of older workers (aged 50-59). Interestingly, the reduction in the number of hierarchical layers seems to have the

\footnotetext{
${ }^{8}$ The question is phrased as follows: "In the workshops of your firm, who is entitled to: (1) fine-tune the apparels (2) operate basic maintenance (3) allocate tasks among operators (4) control the quality of supplies (5) control the quality of the product (6) participate to performance improvement (7) participate to projectmanagement teams (8) stop the production process in case of incident (9) make a first diagnosis in case of incident (10) start production again when stopped because of incident". For each question, the survey offers three possible answers: "hierarchy, operator, specialist". The questions are asked for 1994 and 1997. We give value 1 to each answer involving an operator so that the aggregate responsibility indicator varies between 0 and 10. Our D_RESP variable is then defined as the difference between the aggregate indicators for 1997 and 1994.

${ }^{9}$ TRAIN_X $=$ [(number of employees from age group $X$ receiving training) / number of employees in age group $\mathrm{X})$ ] / [(total number of trainees in the firm / total number of employees in the firm)].

${ }^{10}$ The relative rates of training for the three age groups are not strictly collinear as long as the age groups do not have the same size.
} 
opposite effect: it is correlated to an increase in the share of workers aged 50-59 and to a reduction in the share of younger employees (aged 30-39). This result suggests that the decentralisation of the production process associated with the reduction in the number of hierarchical layers may generate some form of return to experience which positively affects the employment and/or wage prospects of older workers.

The relationships between innovation and change in the age structure of the workforce are confirmed when re-estimating our model within occupational categories (see Table 2). The age bias is particularly strong within the managerial group. The Internet positively affects the wage bill share of managers as a whole, but this effect is much stronger for managers aged 30-39 than for older managers. Similarly, the introduction of network-interconnected computers and the increase in the amount of responsibility awarded to operators appear to be negatively correlated with the wage bill share of older managers. These effects are far less stark for clerks since only the Internet has any significant effect. However, the correlation between its adoption and the wage bill share of the various age groups appears to be negative for the 30-39 year olds and positive for the 40-49 year olds which does not support the age bias hypothesis. In contrast, the adoption of the Internet is associated with a decrease in the proportion of blue-collars and this effect is stronger for older blue-collars than for any other age group. Interestingly, the positive correlation between the reduction in the number of hierarchical layers and the wage bill share of older workers found in Table 1 seems to be almost entirely due to managers. This "pro-age" bias does not exist for clerks and even seems to change sign for blue-collars: the flattening of the hierarchical structure is indeed associated with an increase in the share of the youngest age group (20-29 years old) at the expense of the 30-39 year olds. This result suggests that if experience may become an asset when the hierarchical structure flattens, this only occurs for the most highly skilled workers.

Beyond the impact on the age structure of the workforce, our results confirm that the introduction of the Internet as well as the reduction in the number of hierarchical layers tend to shift the occupational structure upward, towards managers and at the expense of bluecollars. This is consistent with the results in the literature on skill-biased technical and organisational change (see Bresnahan et al, 2002 and Caroli et Van Reenen, 2001).

Overall, our results suggest that technological and organisational innovations are biased against older workers and in favour of younger ones. This bias is particularly strong among managers. It is generated by all types of new technologies and innovative work practices, except the flattening of the hierarchical structure, which seems to be instead rather favourable 
to older workers.

The issue we want to tackle here is: do firms' investments in training allow to mitigate the age bias generated by the adoption of ICT and innovative work practices? As a first step, we regress the change in the wage bill share of the various age groups on the relative training rate of each group. ${ }^{11}$ To the extent that our data comes from two different sources, the age groups used to build the relative training rates - younger than 25 years old, 25-44 years old and 45 years old and above - do not exactly correspond to the ones we use to capture the change in the age structure of the workforce. The results presented in Table 3 show that training of older workers (TRAIN_3) is associated with a subsequent increase in the share of the wage bill accruing to them. The higher the relative training rate of workers aged 45 and above as compared to average training in the firm in 1995-1997, the greater the increase in their wage bill share over 1998-2000, all other things equal. In contrast, training of older workers has a negative impact on the change in the wage bill share of workers aged 30-39. Interestingly, there is no similar effect of the relative training rates of younger age groups: TRAIN_1 and TRAIN_2 are not significantly correlated to changes in the wage bill share of the corresponding age groups.

When re-estimating our model within different occupations, the relationship between the relative training rate of older workers and their share in the wage bill is less stark (see Table 4). This may be due to the shortcomings of our data. Ideally, we would have correlated the relative rate of training of the various age groups of managers with the change in the age structure of the workforce among managers; and similarly for clerks and blue-collars. However, our training data does not include information on training rates by age and occupation. So, we can only correlate the relative training rate in each age group - as computed for all occupations - with the change in the age structure of the workforce within our three occupational categories. This imperfect correspondence may result in an attenuation bias. In our view, such an exercise is however interesting in order to detect which occupations are most sensitive to changes in the relative training rates. As indicated by results in Table 4 , the relative training rate of workers aged 45 and above is still positively correlated to an increase in their wage bill share, but the coefficient is only significant for clerks (and at the $10 \%$ level). ${ }^{12}$ However, training of older workers is persistently associated with a decrease in

\footnotetext{
${ }^{11}$ The relative training rate of age group $\mathrm{X}$ is defined as the training rate in age group $\mathrm{X}$ divided by the average training rate in the firm's workforce.

${ }^{12}$ The fact that the estimates are less often statistically significant may be due in principle to reduced precision at this disaggregated level. However, point estimates also tend to be lower.
} 
the wage bill share of younger age groups: this is the case for workers aged 20-29 in managerial occupations and for workers aged 30-39 among blue-collars. Overall, greater access to training for older workers between 1995 and 1997 is associated with a change in the age structure of the workforce at the expense of younger workers, and in favour of older ones in the next period (1998-2000). A similar result is obtained for middle-aged workers (25-44 years old): among clerks, the relative training rate of workers aged 25-44 is negatively correlated to the change in the wage bill share of the youngest age group (20-29 years old) and positively correlated with the share of workers who are directly affected by the training (at least for those aged 40-49). Moreover, training of middle-aged clerks is negatively associated with the change in the wage bill share of the oldest age group within the clerk category (50-59 years old). These results are not surprising given the definition of our training indicators: if middle-aged workers have been trained more than average over the 1995-1997 period, this means that older and/or younger workers have been trained less. So, the decrease in their wage bill share over the next period just confirms the existence of a relationship between training and change in the age structure of the workforce in favour of those age groups who have been directly affected by training. However, this result does not hold for blue-collars, training of workers aged 25-44 is indeed associated with an increase in the wage bill share of older workers (aged 50-59) and with a decrease in that of workers aged 40-49. Finally, the relative training rate of the youngest age group (less than 25 years old) is not significantly correlated to any change in the age structure of the workforce.

These results hold when introducing training, ICT and organizational innovations simultaneously in the regressions (see Table 5). The adoption of the Internet, of networkinterconnected computers as well as the increase in the amount of responsibility awarded to operators still appear to be age biased, whereas the flattening of the hierarchical structure is, here again, associated with an increase in the wage bill share of older workers at the expense of workers aged 30-39. As regards the role of training, here again, only the relative training of older workers seems to affect the age structure of the workforce: in a positive way for workers aged 50-59 and in a negative way for the 30-39 year olds.

The model we have estimated so far was derived from a translog cost function so that we have focused on changes in the wage bill shares. However, one may wonder whether the observed correlations are due to changes in the share of the various age groups in employment or, alternatively, to changes in relative wages. In order to tackle this issue, we re-estimate equation (3) on the shares of the 4 age groups in employment - more precisely, in 
the number of days worked. The corresponding results are presented in Table 6. The coefficients on the innovation variables are close to those obtained in Table 5, but some of them are less precisely estimated. The Internet is still biased against older workers but the positive correlation with the share of workers aged 30-39 in employment is not significant. Symmetrically, the introduction of network-interconnected computers and the increase in the amount of responsibility awarded to operators are still positively associated with the share of young workers (aged 30-39) but the negative correlation with the share of older workers is no longer significant. By contrast, the decrease in the number of hierarchical layers has the same effect on employment as on wage bill shares: it is positive for older workers and negative for younger ones. As regards training, it does not affect the age structure of employment when focused on young and middle-aged workers. As was the case for the wage bill shares, the only significant results are for the relative training rate of older workers which negatively affects the share of workers aged 30-39 in employment but positively affects that of workers aged 40-49, while it has no effect on the oldest age group - whereas the opposite held in Table 5. Overall, the results we obtained on wage bill shares seem to be largely driven by effects on the age structure of employment, but in some cases relative wages play a role too. Regarding the introduction of network-interconnected computers and the increase in the amount of responsibility awarded to operators, the negative correlation with the wage bill share of older workers evidenced in Table 5 seems to be mostly due to a decrease in their relative wage, rather than to a decrease in their share in employment. ${ }^{13}$ Similarly, the positive impact of the relative rate of training of older workers on the subsequent change in their wage bill share would essentially go through an impact on the relative wages of older workers, rather than an increase in their share in total employment.

On average, access to training for workers aged 45 and more seems to have a positive impact on their employment and wage prospects: on their share in employment for those aged 40 to 49 and on their relative wage for the oldest group (aged 50-59). Let us underline however that training of older workers does not reduce the age bias due to the introduction of ICT and innovative work practices. Table 7 presents the estimates of a specification, similar to that used in Table 5, but in which we interact the relative rate of training of older workers with our innovation variables. The coefficients on the interaction terms are not very encouraging.

\footnotetext{
${ }^{13}$ For instance, the coefficient on the introduction of network-interconnected computers is -.44 (significant at $10 \%$ ) when considering the wage bill share of workers aged 50 to 59 as the dependent variable, and only -.16 (not statistically significant) when considering their employment share. Note however that standard errors are large, so that the difference in point estimates is only suggestive, but not statistically significant.
} 
While the Internet does not seem to have much effect on the wage bill shares of the various age groups per se, the correlation becomes positive for the youngest age group (20-29 years old) and negative for workers aged 40-49 when introduced in firms which invest in training in a disproportionate way for older workers. Similarly, while the flattening of the hierarchical structure seems to have a negative effect on workers in their 30 s per se, this effect vanishes in firms where older workers receive more training than average. The only case in which training of older workers seems to dampen the age bias due to innovation is for responsibilities awarded to operators: while the direct effect of this new organisational practice is negative for the wage bill share of the oldest age group, it is strongly attenuated when older workers have been trained more than average in the previous period.

Overall, technological and organisational innovations on the one hand and training on the other hand seem to have opposite effects on the age structure of the workforce - except for the flattening of the hierarchical structure. However, our results do not provide evidence that training would reduce the age bias due to the introduction of ICT and innovative work practices.

\subsection{Employment flows by age group, innovation and training}

The results presented in Table 8 analyse inflows and outflows of workers both on average and for each age group. These flows relate to all types of labour contracts, be they permanent or temporary.

The impact of ICT and innovative work practices on the age structure of employment inflows and outflows appears to be quite varied according to the type of innovation under study. The adoption of the Internet increases hirings without affecting separations, whereas the introduction of network-interconnected computers and the reduction in the number of hierarchical layers do not seem to affect the aggregate level of inflows and outflows. As regards the increase in the amount of responsibility awarded to operators, it contributes to reduce turnover as a whole given its negative effect on both hirings and separations. The same holds for training of younger and middle-aged workers which is negatively correlated both with inflows and outflows. As regards the relative rate of training of older workers, it is also associated with a reduction in inflows, but does not seem to be significantly correlated with outflows.

Coming now to the differential impact on the inflows and outflows of the various age groups, 
younger workers appear to be positively affected by the Internet: it increases hirings of workers aged 20-29 more than average while reducing their outflow. The opposite holds for older age groups since the Internet is associated with an increase in outflows (with no increase in inflows) for workers aged 30-39 and to a small - or zero - increase in hirings (with no impact on separations) for workers aged 40 and above. The introduction of networkinterconnected computers reduces hirings in a significant way in the youngest age group, but it also reduces separations. The opposite holds for older workers for whom outflows increase when network-interconnected computers are introduced. The reduction in the number of hierarchical layers increase inflows of workers aged 20-29 and reduces those of workers aged 30-39 whereas it does not seem to affect the age structure of outflows. In contrast, increasing responsibility of operators has no impact on the age structure of inflows, whereas it has a clear negative effect on older workers as far as separations are concerned: D_RESP raises outflows of workers aged 40-49 and 50-59 while it reduces separations in the youngest age group.

As regards training investments made by firms, they strongly affect hirings and separations of the age groups which are directly affected by the training. The relative rate of training of workers aged 25 years old and below reduces outflows more than average in the corresponding age group (i.e. workers aged 20-29), without affecting inflows. In parallel it negatively affects older workers by increasing their rate of turnover (increase in hirings and in separations). Regarding training of middle-aged workers (25-44 years old) it reduces outflows in the 30-39 age group more than average as well as the rate of turnover of workers aged 4049. In contrast, it negatively affects older workers as compared to younger age groups, to the extent that it does not affect their outflows while substantially reducing those of middle-aged workers. Finally, training of older workers tends to protect them since it reduces their inflow much less than in other age groups (aged 30-39 and 40-49). Moreover, regarding workers aged 40-49, it sharply reduces inflows but also outflows so that it contributes to a strong reduction in the rate of turnover.

Overall, it seems that a large part of the effect of innovation and training on workers' flows by age group goes through turnover. The adoption of network-interconnected computers reduces the rate of turnover among the youngest age group. In contrast, their relative training rate increases the turnover of older workers. Finally, training of middle-aged and older workers contributes to the reduction of the rate of turnover among the 40-49 year old group. Moreover, when innovations and training only affect hirings or separations, our results 
suggest that ICT and innovative work practices have a negative impact on older workers as compared to other age groups. This occurs either because innovations raise the inflow of older workers less than average (e.g. Internet for the 40-49 and 50-59 year olds) or because they increase their outflows relative to other age groups (e.g. network-interconnected computers and increase in the responsibility of operators for employees aged 50 and above). In contrast, training seems to protect the categories of workers who are directly affected, either by increasing their hirings as compared to the other age groups - as is the case for older workers - or by reducing their separations - as is the case for the youngest group and for middle-aged workers.

All in all, the analysis of employment flows confirms the results obtained when estimating the wage bill share model: ICT and innovative work practices negatively affect the employment prospects of older workers, whereas concentrating training investments on them helps stabilise their share in the wage bill in the next period.

\section{Conclusion}

Our research confirms that ICT and innovative work practices are biased against older workers. This is the way we interpret the negative correlation that we find between technological and organisational innovations on the one hand and subsequent change in the wage bill share of older workers on the other hand. This results holds with various measures of technological and organisational change, namely the introduction of the Internet, the introduction of network-interconnected computers and the increase in the amount of responsibility awarded to operators: all three innovative devices increase the share of workers in their 30s and reduce that of older workers in the wage bill and, to a smaller extent, in employment. Interestingly, in contrast, the flattening of the hierarchical structure appears to be favourable to older workers - and correspondingly unfavourable to workers aged 30-39: it increases the share of workers aged 50-59 both in the wage bill and in employment. One reason for this may be that tacit knowledge plays an important role when flattening the hierarchical structure. Skills acquired by older workers through learning-by-doing are all the more necessary to firms that they incorporate an important part of tacit knowledge which is hardly substitutable. When this is the case, older workers possess a valuable asset which may enhance their employability. When flattening the hierarchical structure of the firm, tacit knowledge held by workers is likely to become more important, in particular as regards communication and work organisation. Older workers then benefit from a comparative 
advantage which does not exist when technological and organisational innovations generate greater knowledge codification. Such a mechanism could account for the positive impact of the reduction in hierarchical layers upon the employment prospects of older workers.

Moreover, our results suggest that training tends to protect older workers in terms of employment and/or earnings. The relative training rate of workers aged 45 and above is indeed associated with an increase in their share in employment (for those aged 40-49) or in the wage bill (for the 50-59 age group). Thus doing, it contributes to offset the negative effects of ICT and innovative work practices on older workers. However, let us underline that training does not reduce the age bias associated with technological and/or organisational innovations to the extent that the interaction terms between innovations and training are either insignificant or negative in the models that we estimate. So, although training has a positive impact on employment and earnings of older workers, it offers only limited prospects to enhance their employability, in a context where technological and organisational innovations tend to develop.

These results are obtained by estimating changes in the wage bill and employment shares of the various age groups. We get very similar patterns when estimating employment flows. Our results suggest that technological and organisational innovations have mostly negative effects on older workers in relative terms, either because they raise hirings less than average or because they increase separations in a disproportionate way in the oldest age group. In contrast, training investments reduce turnover but also protect those groups of workers who are directly affected by the training, either by increasing hirings as compared to other age groups - as is the case for older workers - or by reducing separations - as happens for younger or middle-aged workers.

Our research suggests that policies aiming at increasing the employability of older workers cannot entirely rely on training in a world where technological and organisational innovations are expanding. More has to be done in order to help older workers adapt to the new communication and organisational devices. One option probably consists in awarding workers more time to adjust to the new production methods - see Jolivet (2003). This is of course a challenge in a context of increasing competition and globalisation of economic activities. However, given the rhythm at which population is ageing in most developed countries, this challenge has to be met in order to maintain older workers in employment. 


\section{References}

Aubert Patrick, Eve Caroli and Muriel Roger, 2006a, " New Technologies, Organisation and Age: Firm-Level Evidence", Economic Journal, 116, pp. 73-93.

Bartel A. and Sicherman N, 1993, "Technological Change and Retirement Decisions of Older Workers", Journal of Labor Economics, 11(1), pp. 162-83.

Bassanini Andrea, 2006, "Training, wages and employment security: an empirical analysis on European data", Applied Economics Letters, 13(8), pp. 523-27.

Beckmann M., 2007, "Age-biased technological and organizational change: Firm-level evidence and Management Implications”, Discussion Paper $n^{\circ} 05 / 07$, Faculty of Business and Economics, University of Basel.

Ben Porath Yoram, 1967, "The Production of Human Capital and the Life Cycle of Earnings", Journal of Political Economy, 75(4), pp. 352-65.

Biscourp Pierre, Bruno Crepon, Thomas Heckel and Nicolas Riedinger, 2002, "How do firms respond to cheaper computers? Microeconometric evidence for France based on a production function approach", Economie et Statistique n³55-356, pp. 3-20.

Boldrin Michele, Juan Dolado, Juan Jimeno and Franco Peracchi, 1999, "The Future of Pensions in Europe", Economic Policy, 14(29), pp. 289-320.

Borghans L. and Ter Weel B, 2002, "Do Older Workers Have More Trouble Using a Computer than Younger Workers?", in A. de Grip, J. van Loo and K. Mayhew eds: "The Economics of Skills Obsolescence", Research in Labor Economics, vol. 21, pp. 139-73.

Bresnahan Timothy, Erik Brynjolfsson and Lorin Hitt, 2002, "Information technology, workplace organization, and the demand for skilled labor: firm-level evidence", Quarterly Journal of Economics, 117(1), pp. 339-76.

Caroli Eve and John Van Reenen, 2001, "Skill biased organizational change? Evidence from a panel of British and French establishments", The Quarterly Journal of Economics, 116(4), pp. 1449-92.

Friedberg L, 2003, "The impact of Technological Change on Older Workers: Evidence from Data on Computer Use", Industrial and Labor Relations Review, 56(3), pp. 511-29.

Haegeland Torbjorn, Dag Ronningen and Kjell Salvanes, 2007, "Adapt or withdraw? Evidence on technological changes and early retirement using matched worker-firm data", Statistics Norway, Research Department Discussion Paper n509.

Jolivet Annie, 2003, « The cluster of issues surrounding working time, work organisation and job design », in M. Jepsen, D. Foden, M. Hutsebaut (eds), A lifelong strategy for active ageing, ETUI, Brussels, pp. 123-156.

de Koning Jaap and Arie Gelderblom, 2006, "ICT and older workers: no unwrinkled relationship", International Journal of Manpower, 27(5), pp. 467-90.

Ronningen Dag, 2007, "Are technological change and organizational change biased against older workers? Firm-level Evidence", Statistics Norway, Research Department Discussion Paper $n^{\circ} 512$.

Schleife Katrin, 2006, "Computer Use and Employment Status of Older Workers - An Analysis based on Individual Data", Labour, 20(2), pp. 325-48. 
Schleife Katrin, 2008, "IT Training and Employability of Older Workers", ZEW Discussion Paper $n^{\circ}$ 08-021.

Song Younghwan, 2009, "Training, Technological Changes and Displacement", Journal of Labor Research, 30(3), pp. 201-18.

Wooldridge J., 2002, Econometric Analysis of Cross Section and Panel Data, MIT Press, Cambrige. 


\section{Results}

\section{Table 1 : Change in the age structure of the workforce and innovation 1998-2000}

(coefficients $\mathrm{x} 100)$

Change in the wage bill share

Age 20-29 Age 30-39 Age 40-49 Age 50-59

\begin{tabular}{lcccc} 
Internet & 0.10 & $0.52^{* *}$ & 0.06 & $-0.68^{* *}$ \\
Introduction of network-interconnected & $(0.23)$ & $(0.26)$ & $(0.28)$ & $(0.27)$ \\
computers (D_COMP) & 0.07 & 0.41 & -0.05 & -0.43 \\
Reduction in the number of hierarchical & $(0.23)$ & $(0.26)$ & $(0.28)$ & $(0.27)$ \\
layers (D_HIERAR) & 0.12 & $-0.70^{* *}$ & -0.13 & $0.72^{* *}$ \\
Increase in the amount of responsibility & $(0.29)$ & $(0.33)$ & $(0.35)$ & $(0.34)$ \\
awarded to operators (D_RESP) & 0.01 & $0.16^{* *}$ & -0.04 & $-0.13^{*}$ \\
\hline \hline
\end{tabular}

Sample size: 2,352 Firms.

Note :

1. The results in this table are the outcomes of joint estimates of wage bill shares for all age groups except the youngest one by joint generalised least squares (JGLS). Basic controls include four size and five industry dummies as well as the 1998-2000 change in relative wages, log value-added and log of physical capital. We also control for the age structure of the workforce as of 1994. Innovation and training variables refer to the 1995-1997 period.

2. The coefficients for the youngest age group (20-29 years old) are estimated using the following homogeneity conditions :

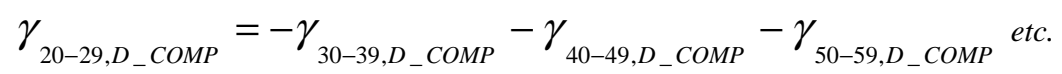

3 Estimated standard errors asymptotically robust to heteroskedasticity, are reported in parentheses. Estimates which are significant at the $5(10) \%$ level are indicated by $* *(*)$. 
Table 2 : Innovation and change in the age structure of the workforce, by occupation 1998-2000 (coefficients $\mathrm{x} 100)$

\begin{tabular}{lccccc}
\hline \hline \multicolumn{2}{l}{ Managers and technicians (Change in the wage bill share) } & & & \\
\hline & Managers & Age 20-29 & Age 30-39 & Age 40-49 & Age 50-59 \\
\hline Internet & $0.17^{*}$ & -0.23 & $0.44^{* *}$ & 0.25 & $-0.46^{*}$ \\
Introduction of network-interconnected & $(0.10)$ & $(0.14)$ & $(0.20)$ & $(0.25)$ & $(0.25)$ \\
computers (D_COMP) & 0.07 & 0.01 & 0.28 & 0.25 & $-0.54^{* *}$ \\
Reduction in the number of hierarchical & $(0.10)$ & $(0.14)$ & $(0.19)$ & $(0.24)$ & $(0.25)$ \\
layers (D_HIERAR) & $0.21^{*}$ & $-0.34^{*}$ & -0.25 & -0.22 & $0.81^{* * *}$ \\
Increase in the amount of responsibility & $(0.13)$ & $(0.18)$ & $(0.24)$ & $(0.30)$ & $(0.31)$ \\
awarded to operators (D_RESP) & 0.01 & 0.03 & $0.11^{* *}$ & -0.00 & $-0.14^{* *}$ \\
\hline
\end{tabular}

Clerks (Change in the wage bill share)

\begin{tabular}{lccccc}
\hline & Clerks & Age 20-29 & Age 30-39 & Age 40-49 & Age 50-59 \\
\hline Internet & -0.01 & 0.11 & $-0.20^{* *}$ & $0.14 *$ & -0.05 \\
Introduction of network-interconnected & $(0.06)$ & $(0.07)$ & $(0.09)$ & $(0.08)$ & $(0.07)$ \\
computers (D_COMP) & -0.02 & 0.01 & -0.03 & 0.00 & 0.01 \\
Reduction in the number of hierarchical & $(0.06)$ & $(0.07)$ & $(0.09)$ & $(0.08)$ & $(0.07)$ \\
layers (D_HIERAR) & 0.02 & -0.05 & 0.13 & -0.12 & 0.04 \\
Increase in the amount of responsibility & $(0.07)$ & $(0.10)$ & $(0.11)$ & $(0.10)$ & $(0.09)$ \\
awarded to operators (D_RESP) & -0.01 & 0.00 & -0.01 & 0.00 & 0.00 \\
\hline
\end{tabular}

Blue-Collars (Change in the wage bill share)

\begin{tabular}{lccccc}
\hline & Blue-collars & Age 20-29 & Age 30-39 & Age 40-49 & Age 50-59 \\
\hline Internet & $-0.17^{*}$ & 0.05 & 0.24 & 0.02 & $-0.31^{*}$ \\
Introduction of network-interconnected & $(0.10)$ & $(0.19)$ & $(0.19)$ & $(0.20)$ & $(0.16)$ \\
computers (D_COMP) & -0.06 & 0.05 & 0.21 & -0.12 & -0.14 \\
Reduction in the number of hierarchical & $(0.10)$ & $(0.18)$ & $(0.18)$ & $(0.19)$ & $(0.16)$ \\
layers (D_HIERAR) & $-0.23^{*}$ & $0.44^{*}$ & $-0.44^{*}$ & -0.00 & -0.00 \\
Increase in the amount of responsibility & $(0.12)$ & $(0.23)$ & $(0.23)$ & $(0.25)$ & $(0.20)$ \\
awarded to operators (D_RESP) & 0.00 & -0.03 & 0.07 & -0.04 & -0.01 \\
\hline \hline
\end{tabular}

Sample size: 2,352 Firms.

Note :

1. The coefficients $\tilde{\hat{\gamma}}$ are computed using the coefficients $\hat{\gamma}$ estimated for Internet, D_COMP,D_HIERAR and D_RESP by the joint generalised least squares (JGLS). The $\hat{\gamma}$ estimates for managers and technicians aged 20 to 29 years old are obtained by the homogeneity conditions. The overall impact of on the wage-bill share of an age-by-occupation group is the sum of the average occupation effect and the differential age effect. The coefficients that are reported for an occupation are averages over the 4 age groups in the occupation:

$\tilde{\hat{\gamma}}_{D_{-} \text {COMP }}^{\text {Blue-collars }}=\frac{1}{4}\left(\hat{\gamma}_{D_{-} \text {COMP }}^{\text {20-29,Blue-collars }}+\hat{\gamma}_{D_{-} \text {COMP }}^{30-39, \text { Blue-collars }}+\hat{\gamma}_{D_{-} \text {COMP }}^{40-49 \text { Blue-collars }}+\hat{\gamma}_{D_{-} \text {COMP }}^{50-59 \text { Blue-collars }}\right)$

2. The coefficients for each age group within one occupation are net of the average effect in the occupation:

$\tilde{\hat{\gamma}}_{D_{-} \text {COMP }}^{40-49, \text { Blue-collars }}=\hat{\gamma}_{D_{-} \text {COMP }}^{40-49}-\tilde{\hat{\gamma}}_{D_{-} \text {COMP }}^{\text {Blue-collars }}$

3. Control variables include four size and five industry dummies as well as the 1998-2000 change in log value-added and log of physical capital. We also control for the age structure of the workforce as of 1994. Innovation and training variables refer to the 1995-1997 period.

4. Estimated standard errors asymptotically robust to heteroskedasticity, are reported in parentheses. Estimates which are significant at the $5(10) \%$ level are indicated by **(*). 
Table 3 : Change in the age structure of the workforce and training

1998-2000

(coefficients $\mathrm{x} 100$ )

Change in the wage bill share

Age 20-29

Age 30-39

Age 40-49

Age 50-59

Relative training rate of employees below 25

$-0.07$

$-0.04$

0.04

0.07

years old (TRAIN_1)

(0.08)

$(0.09)$

$(0.10)$

$(0.09)$

Relative training rate of employees aged 25

to 44 years old (TRAIN_2)

$-0.26$

0.36

$-0.07$

$(0.22)$

$(0.25)$

$(0.27)$

$-0.03$

$-0.12$

$-0.80 * * *$

0.30

$(0.26)$

$(0.22)$

$(0.24)$

$(0.26)$

$0.62 * *$

years old and above (TRAIN_3)

Sample size: 2,352 Firms.

Note :

1. The relative training rate of age group $X$ is defined as the training rate in age group $X$ divided by the average training rate in the firm's workforce.

2. The results in this table are the outcomes of joint estimates of wage bill shares for all age groups except the youngest one by joint generalised least squares (JGLS). Basic controls include four size and five industry dummies as well as the 1998-2000 change in relative wages, log value-added and log of physical capital. We also control for the age structure of the workforce as of 1994. Innovation and training variables refer to the 1995-1997 period.

3. The coefficients for the youngest age group (20-29 years old) are estimated using the following homogeneity conditions :

$\gamma_{20-29, \text { TRAIN_1 }}=-\gamma_{30-39, \text { TRAIN_1 }}-\gamma_{40-49, \text { RRAIN_1 }_{1}}-\gamma_{50-59, \text { TRAIN_1 }}$ etc.

4. Estimated standard errors asymptotically robust to heteroskedasticity, are reported in parentheses. Estimates which are significant at the $5(10) \%$ level are indicated by $* * * *$. 


\section{Table 4 : Training and change in the age structure of the workforce, by occupation 1998-2000}

(coefficients $\mathrm{x} 100)$

\begin{tabular}{lccccc}
\hline \hline \multicolumn{2}{l}{ Managers and technicians (Change in the wage bill share) } & & & \\
\hline & Managers & Age 20-29 & Age 30-39 & Age 40-49 & Age 50-59 \\
\hline Relative training rate of employees & -0.02 & $-0.08^{*}$ & -0.05 & 0.10 & 0.03 \\
below 25 years old (TRAIN_1) & $(0.03)$ & $(0.05)$ & $(0.07)$ & $(0.08)$ & $(0.08)$ \\
Relative training rate of employees aged & $0.22^{* *}$ & -0.07 & 0.08 & 0.19 & -0.20 \\
25 to 44 years old (TRAIN_2) & $(0.10)$ & $(0.14)$ & $(0.19)$ & $(0.23)$ & $(0.24)$ \\
Relative training rate of employees aged & 0.07 & $-0.26^{* *}$ & -0.15 & 0.06 & 0.35 \\
45 years old and above (TRAIN_3) & $(0.09)$ & $(0.13)$ & $(0.18)$ & $(0.23)$ & $(0.23)$ \\
\hline
\end{tabular}

Clerks (Change in the wage bill share)

\begin{tabular}{lccccc}
\hline & Clerks & Age 20-29 & Age 30-39 & Age 40-49 & Age 50-59 \\
\hline Relative training rate of employees & 0.01 & 0.02 & -0.05 & 0.04 & -0.01 \\
below 25 years old (TRAIN_1) & $(0.02)$ & $(0.02)$ & $(0.03)$ & $(0.03)$ & $(0.02)$ \\
Relative training rate of employees aged & -0.02 & $-0.12^{*}$ & 0.01 & $0.28^{* * *}$ & $-0.16^{* *}$ \\
25 to 44 years old (TRAIN_2) & $(0.05)$ & $(0.07)$ & $(0.08)$ & $(0.08)$ & $(0.07)$ \\
Relative training rate of employees aged & 0.02 & -0.05 & -0.11 & 0.04 & $0.12^{*}$ \\
45 years old and above (TRAIN_3) & $(0.05)$ & $(0.07)$ & $(0.08)$ & $(0.08)$ & $(0.07)$ \\
\hline
\end{tabular}

Blue-Collars (Change in the wage bill share)

\begin{tabular}{lccccc}
\hline & Blue-Collars & Age 20-29 & Age 30-39 & Age 40-49 & Age 50-59 \\
\hline Relative training rate of employees & 0.00 & 0.05 & -0.02 & -0.09 & 0.06 \\
below 25 years old (TRAIN_1) & $(0.03)$ & $(0.06)$ & $(0.06)$ & $(0.07)$ & $(0.05)$ \\
Relative training rate of employees aged & $-0.21^{* *}$ & -0.12 & 0.28 & $-0.45^{* *}$ & $0.30^{* *}$ \\
25 to 44 years old (TRAIN_2) & $(0.09)$ & $(0.18)$ & $(0.18)$ & $(0.19)$ & $(0.15)$ \\
Relative training rate of employees aged & -0.09 & 0.15 & $-0.41^{* *}$ & 0.19 & 0.07 \\
45 years old and above (TRAIN_3) & $(0.09)$ & $(0.17)$ & $(0.17)$ & $(0.18)$ & $(0.15)$ \\
\hline \hline
\end{tabular}

Sample size: 2,352 Firms.

Note :

1. The relative training rate of age group $X$ is defined as the training rate in age group $X$ divided by the average training rate in the firm's workforce.

2. The coefficients $\tilde{\hat{\gamma}}$ are computed using the coefficients $\hat{\gamma}$ estimated for TRAIN_1, TRAIN_2 and TRAIN_3 by the joint generalised least squares (JGLS). The $\hat{\gamma}$ estimates for managers and technicians aged 20 to 29 years old are obtained by the homogeneity conditions. The overall impact of on the wage-bill share of an age-by-occupation group is the sum of the average occupation effect and the differential age effect. The coefficients that are reported for an occupation are averages over the 4 age groups in the occupation:

$\tilde{\hat{\gamma}}_{\text {TRAIN_1 }}^{\text {Blue-collars }}=\frac{1}{4}\left(\hat{\gamma}_{\text {TRAIN_1 }}^{\text {20-29,Blue-collars }}+\hat{\gamma}_{\text {TRAIN_1 }}^{\text {30-39,Blue-collars }}+\hat{\gamma}_{\text {TRAIN_1 }}^{40-49, \text { Blue-collars }}+\hat{\gamma}_{\text {TRAIN_1 }}^{\text {50-59,Blue-collars }}\right)$

3. The coefficients for each age group within one occupation are net of the average effect in the occupation:

$\tilde{\hat{\gamma}}_{\text {TRAIN_B }}^{40-49, \text { Blue-collars }}=\hat{\gamma}_{\text {TRAIN_1 }}^{40-49}-\tilde{\hat{\gamma}}_{\text {TRAIN_1 }}^{\text {Blue-collars }}$

4. Control variables include four size and five industry dummies as well as the 1998-2000 change in log value-added and log of physical capital. We also control for the age structure of the workforce as of 1994. Innovation and training variables refer to the 1995-1997 period.

5. Estimated standard errors asymptotically robust to heteroskedasticity, are reported in parentheses. Estimates which are significant at the $5(10) \%$ level are indicated by $* * *)$. 
Table 5 : Change in the age structure of the workforce, innovation and training 1998-2000

(coefficients $\mathrm{x} 100)$

Change in the wage bill share

Age 20-29 Age 30-39 Age 40-49 Age 50-59

\begin{tabular}{lcccc} 
Internet & 0.11 & $0.55^{* *}$ & 0.05 & $-0.71^{* * *}$ \\
Introduction of network-interconnected & $(0.23)$ & $(0.26)$ & $(0.28)$ & $(0.27)$ \\
computers (D_COMP) & 0.08 & $0.42^{*}$ & -0.06 & $-0.44^{*}$ \\
Reduction in the number of hierarchical & $(0.23)$ & $(0.26)$ & $(0.28)$ & $(0.27)$ \\
layers (D_HIERAR) & 0.14 & $-0.67 * *$ & -0.15 & $0.68^{* *}$ \\
Increase in the amount of responsibility & $(0.29)$ & $(0.33)$ & $(0.35)$ & $(0.34)$ \\
awarded to operators (D_RESP) & 0.01 & $0.16^{* * *}$ & -0.04 & $-0.13^{*}$ \\
Relative training rate of employees below 25 & $(0.06)$ & $(0.06)$ & $(0.07)$ & $(0.07)$ \\
years old (TRAIN_1) & -0.07 & -0.04 & 0.04 & 0.06 \\
Relative training rate of employees aged 25 & $(0.08)$ & $(0.09)$ & $(0.10)$ & $(0.09)$ \\
to 44 years old (TRAIN_2) & -0.27 & 0.33 & -0.06 & 0.00 \\
Relative training rate of employees aged 45 & $(0.22)$ & $(0.25)$ & $(0.27)$ & $(0.26)$ \\
years old and above (TRAIN_3) & -0.13 & $-0.83^{* * * *}$ & 0.31 & $0.65^{* * *}$ \\
\hline \hline
\end{tabular}

Sample size: 2,352 Firms.

Note :

1. The relative training rate of age group $X$ is defined as the training rate in age group $X$ divided by the average training rate in the firm's workforce.

2. The results in this table are the outcomes of joint estimates of wage bill shares for all age groups except the youngest one by joint generalised least squares (JGLS). Basic controls include four size and five industry dummies as well as the 1998-2000 change in relative wages, log value-added and log of physical capital. We also control for the age structure of the workforce as of 1994. Innovation and training variables refer to the 1995-1997 period.

3. The coefficients for the youngest age group (20-29 years old) are estimated using the following homogeneity conditions :

$\gamma_{20-29, D_{-} \text {COMP }}=-\gamma_{30-39, D_{-} \text {COMP }}-\gamma_{40-49, D_{-} \text {COMP }}-\gamma_{50-59, D_{-} C O M P}$ etc.

4. Estimated standard errors asymptotically robust to heteroskedasticity, are reported in parentheses. Estimates which are significant at the $5(10) \%$ level are indicated by $* *(*)$. 
Table 6 : Change in the age structure of the workforce, innovation and training, 1998-2000 Employment shares

(coefficients x100)

Change in the share of each age group in the number of days worked

Age 20-29

Age 30-39

Age 40-49

Age 50-59

Internet

0.32

0.40

0.05

$(0.27)$

$(0.28)$

$(0.27)$

$-0.14$

$-0.77 *$

Introduction of network-interconnected

$-0.16$

$0.45^{*}$

(0.27)

$(0.27)$

$-0.14$

0.27

$-0.68 * *$

$(0.34)$

$(0.34)$

$-0.06$

$(0.35)$

$0.14 * *$

$(0.07)$

$-0.16$

Reduction in the number of hierarchical

0.01

$(0.07)$

0.05

$(0.24)$

Increase in the amount of responsibility

$(0.07)$

$-0.06$

$(0.09)$

$0.55^{*}$

Relative training rate of employees below 25

$(0.10)$

$(0.09)$

$-0.15$

$(0.31)$

$-0.27$

0.25

(0.26)

$-0.09$

$(0.27)$

$(0.26)$

to 44 years old (TRAIN_2)

$-0.26$

$-0.78 * * *$

$0.69 * * *$

$(0.06)$

(0.26)

(0.25)

$(0.25)$

0.02

$(0.08)$

0.17

$(0.24)$

0.35

years old and above (TRAIN_3)

Sample size: 2,352 Firms.

Note :

1 The relative training rate of age group $X$ is defined as the training rate in age group $X$ divided by the average training rate in the firm's workforce.

2. The results in this table are the outcomes of joint estimates of wage bill shares for all age groups except the youngest one by joint generalised least squares (JGLS). Basic controls include four size and five industry dummies as well as the 1998-2000 change in relative wages, log value-added and log of physical capital. We also control for the age structure of the workforce as of 1994. Innovation and training variables refer to the 1995-1997 period.

3. The coefficients for the youngest age group (20-29 years old) are estimated using the following homogeneity conditions :

$\gamma_{20-29, D_{-} \text {СOMP }}=-\gamma_{30-39, D_{-} \text {СOMP }}-\gamma_{40-49, D_{-} \text {СOMP }}-\gamma_{50-59, D_{-} \text {COMP }}$ etc.

4. Estimated standard errors asymptotically robust to heteroskedasticity, are reported in parentheses. Estimates which are significant at the $5(10) \%$ level are indicated by $* *(*)$. 
Table 7 : Change in the age structure of the workforce, innovation and training 1998-2000 Model with interactions (coefficients $\mathrm{x} 100$ )

Change in the wage bill share

Age 20-29

Internet

Introduction of network-interconnected computers (D_COMP)

Reduction in the number of hierarchical layers (D_HIERAR)

Increase in the amount of responsibility awarded to operators (D_RESP)

Relative training rate of employees aged 45 years old and above (TRAIN_3)

Internet $x$ Relative training of employees aged 45 and above (TRAIN_3)

D_COMP $x$ Relative training of employees aged 45 and above (TRAIN_3)

D_HIERAR x Relative training of employees aged 45 and above (TRAIN_3) D_RESP $x$ Relative training of employees aged 45 and above (TRAIN_3)

\begin{tabular}{cccc}
-0.45 & 0.09 & $0.89^{*}$ & -0.54 \\
$(0.39)$ & $(0.43)$ & $(0.47)$ & $(0.45)$ \\
$0.89^{* *}$ & 0.45 & -0.70 & -0.64 \\
$(0.41)$ & $(0.46)$ & $(0.50)$ & $(0.48)$ \\
0.69 & $-2.01^{* * *}$ & 1.09 & 0.23 \\
$(0.70)$ & $(0.78)$ & $(0.85)$ & $(0.82)$ \\
0.05 & $0.24 *$ & 0.06 & $-0.35^{* *}$ \\
$(0.13)$ & $(0.14)$ & $(0.15)$ & $(0.15)$ \\
-0.09 & $-1.05^{* * *}$ & $0.64 *$ & 0.50 \\
$(0.27)$ & $(0.30)$ & $(0.33)$ & $(0.32)$ \\
$0.79 *$ & 0.70 & $-1.22^{* *}$ & -0.27 \\
$(0.45)$ & $(0.50)$ & $(0.54)$ & $(0.52)$ \\
$-1.14 * *$ & -0.06 & 0.92 & 0.27 \\
$(0.48)$ & $(0.53)$ & $(0.58)$ & $(0.56)$ \\
-0.68 & $1.77 *$ & -1.64 & 0.55 \\
$(0.84)$ & $(0.93)$ & $(1.01)$ & $(0.97)$ \\
-0.07 & -0.10 & -0.13 & $\left.0.30^{*}\right)$ \\
$(0.15)$ & $(0.17)$ & $(0.18)$ & $(0.18)$ \\
\hline
\end{tabular}

Sample size: 2,352 Firms.

Note :

1. The relative training rate of age group $X$ is defined as the training rate in age group $X$ divided by the average training rate in the firm's workforce.

2. The results in this table are the outcomes of joint estimates of wage bill shares for all age groups except the youngest one by joint generalised least squares (JGLS). Basic controls include four size and five industry dummies as well as the 1998-2000 change in relative wages, log value-added and log of physical capital. We also control for the age structure of the workforce as of 1994. Innovation and training variables refer to the 1995-1997 period.

3. The coefficients for the youngest age group (20-29 years old) are estimated using the following homogeneity conditions :

$$
\gamma_{20-29, D_{-} \text {COMP }}=-\gamma_{30-39, D_{-} \text {СOMP }}-\gamma_{40-49, D_{-} \text {СOMP }}-\gamma_{50-59, D_{-} \text {COMP }} \text { etc. }
$$

4. Estimated standard errors asymptotically robust to heteroskedasticity, are reported in parentheses. Estimates which are significant at the $5(10) \%$ level are indicated by $* *(*)$. 
Table 8 : Employment inflows and outflows by age group, innovation and training 1998-2000 (coefficients x100)

\begin{tabular}{|c|c|c|c|c|c|}
\hline \multicolumn{6}{|l|}{$\begin{array}{l}\text { Inflows } \\
\end{array}$} \\
\hline & Inflows & Age $20-29$ & Age 30-39 & Age $40-49$ & Age 50-59 \\
\hline Internet & $\begin{array}{l}0.73 * * \\
(0.36)\end{array}$ & $\begin{array}{c}1.17 * * * \\
(0.33)\end{array}$ & $\begin{array}{l}-0.16 \\
(0.18)\end{array}$ & $\begin{array}{c}-0.65 * * * \\
(0.18)\end{array}$ & $\begin{array}{l}-0.36^{*} \\
(0.21)\end{array}$ \\
\hline $\begin{array}{l}\text { Introduction of network-interconnected } \\
\text { computers (D_COMP) }\end{array}$ & $\begin{array}{c}0.32 \\
(0.36)\end{array}$ & $\begin{array}{c}-0.66 * * \\
(0.32)\end{array}$ & $\begin{array}{c}0.25 \\
(0.18)\end{array}$ & $\begin{array}{c}0.08 \\
(0.18)\end{array}$ & $\begin{array}{c}0.32 \\
(0.21)\end{array}$ \\
\hline Reduction in the number of hierarchical & 0.43 & $1.06^{* * *}$ & $-0.58 * * *$ & -0.25 & -0.24 \\
\hline layers (D_HIERAR) & $(0.46)$ & $(0.41)$ & $(0.22)$ & $(0.22)$ & $(0.27)$ \\
\hline $\begin{array}{l}\text { Increase in the amount of responsibility } \\
\text { awarded to operators (D_RESP) }\end{array}$ & $\begin{array}{c}-0.24 * * * \\
(0.09)\end{array}$ & $\begin{array}{l}-0.08 \\
(0.08)\end{array}$ & $\begin{array}{l}0.03 \\
(0.04)\end{array}$ & $\begin{array}{l}0.01 \\
(0.04)\end{array}$ & $\begin{array}{c}0.04 \\
(0.05)\end{array}$ \\
\hline Relative training rate of employees & $-0.32 * * *$ & -0.05 & -0.09 & 0.01 & $0.13^{*}$ \\
\hline below 25 years old (TRAIN_1) & $(0.13)$ & $(0.11)$ & $(0.06)$ & $(0.06)$ & $(0.07)$ \\
\hline Relative training rate of employees aged & $-1.83 * * *$ & 0.24 & -0.22 & $-0.32 *$ & 0.30 \\
\hline 25 to 44 years old (TRAIN_2) & $(0.36)$ & $(0.32)$ & $(0.17)$ & $(0.17)$ & $(0.21)$ \\
\hline Relative training rate of employees aged & $-0.65^{*}$ & $0.52 *$ & $-0.28 *$ & $-0.62 * * *$ & $0.38 *$ \\
\hline 45 years old and above (TRAIN_3) & $(0.35)$ & $(0.31)$ & $(0.17)$ & $(0.17)$ & $(0.20)$ \\
\hline
\end{tabular}

\section{Outflows}

\begin{tabular}{lccccc}
\hline & Outflows & Age 20-29 & Age 30-39 & Age 40-49 & Age 50-59 \\
\hline Internet & 0.35 & $-0.55^{*}$ & $0.36^{* *}$ & -0.04 & 0.24 \\
Introduction of network-interconnected & $(0.42)$ & $(0.31)$ & $(0.18)$ & $(0.18)$ & $(0.24)$ \\
computers (D_COMP) & 0.18 & $-0.73^{* *}$ & 0.10 & -0.07 & $0.70^{* * *}$ \\
Reduction in the number of hierarchical & $(0.42)$ & $(0.30)$ & $(0.18)$ & $(0.18)$ & $(0.24)$ \\
layers (D_HIERAR) & 0.80 & -0.54 & 0.30 & 0.22 & 0.02 \\
Increase in the amount of responsibility & $(0.53)$ & $(0.38)$ & $(0.23)$ & $(0.22)$ & $(0.31)$ \\
awarded to operators (D_RESP) & $-0.18^{*}$ & $-0.24^{* * *}$ & 0.02 & $0.08^{*}$ & $0.15^{* *}$ \\
Relative training rate of employees & $(0.10)$ & $(0.08)$ & $(0.05)$ & $(0.04)$ & $(0.06)$ \\
below 25 years old (TRAIN_1) & $-0.33^{* *}$ & $-0.32^{* * *}$ & -0.02 & 0.05 & $0.29^{* * *}$ \\
Relative training rate of employees aged & $-0.15)$ & $(0.11)$ & $(0.06)$ & $(0.06)$ & $(0.08)$ \\
25 to 44 years old (TRAIN_2) & $(0.41)$ & 0.12 & $-0.72^{* * *}$ & $-0.36^{* *}$ & $0.96^{* * *}$ \\
Relative training rate of employees aged & -0.44 & $0.30)$ & $(0.18)$ & $(0.17)$ & $(0.24)$ \\
45 years old and above (TRAIN_3) & $(0.40)$ & $(0.29)$ & -0.17 & $-0.32^{*}$ & 0.07 \\
\hline \hline
\end{tabular}

Sample size: 6824 firms * year.

Notes:

1. Dependent variables are share of hirings or separations in the firm among the total number of workers in each age group.

2. The relative training rate of age group $X$ is defined as the training rate in age group $X$ divided by the average training rate in the firm's workforce.

3. The coefficients $\hat{\theta}$ are computed using the coefficients $\hat{\beta}$ estimated for Internet, D_COMP, D_HIERAR, D_RESP), TRAIN_1, TRAIN_2 and TRAIN_3 by the joint generalised least squares (JGLS). The $\hat{\beta}$ estimates entrants aged 20 to 29 years old are obtained by the homogeneity conditions:

$\hat{\theta}_{V A R}^{H I R E}=\frac{1}{4} \sum \hat{\beta}_{V A R}^{a^{\prime}, H I R E}$ where $\mathrm{a}^{\prime} \in\{1, \ldots 4\}$ and $\hat{\theta}_{V A R}^{E X I T}=\frac{1}{4} \sum \hat{\beta}_{V A R}^{a^{\prime}, E X I T}$ and where VAR $=$ Internet, D_COMP,D_HIERAR,D_RESP), TRAIN_1, TRAIN_2 and TRAIN_3.

4. The overall impact on the wage-bill share of an age-by-flow group is the sum of the average in- or outflow effect and the differential age effect. The coefficients that are reported for a type of flow are averages over the 4 age groups in the flow category:

$\tilde{\hat{\gamma}}_{\text {VAR }}^{\text {HIRE }}=\frac{1}{4}\left(\hat{\gamma}_{\text {VAR }}^{20-29, H I R E}+\hat{\gamma}_{\text {VAR }}^{30-39, H I R E}+\hat{\gamma}_{\text {VAR }}^{40-49, H I R E}+\hat{\gamma}_{\text {VAR }}^{50-59, H I R E}\right)$

5. The coefficients for each age group within one occupation are net of the average effect in the occupation:

$\hat{\theta}_{V A R}^{30-39, H I R E}=\hat{\beta}_{V A R}^{30-39, H I R E}-\frac{1}{4} \sum \hat{\beta}_{V A R}^{a ', H I R E}$

6. Control variables include four size and five industry dummies as well as the 1998-2000 change in relative wages, log value-added and log of physical capital. We also control for the age structure of the workforce as of 1994. Innovation and training variables refer to the 1995-1997 period.

7. Estimated standard errors asymptotically robust to heteroskedasticity, are reported in parentheses. Estimates which are significant at the $5(10) \%$ level are indicated by ****). 


\section{Appendix}

Appendix Table A.1 : Firm distribution by industy

\begin{tabular}{lcc}
\hline$\%$ of firms in each 1-digit industry & $\begin{array}{c}\text { COI } \\
\text { dataset }\end{array}$ & $\begin{array}{c}\text { Sample used for the } \\
\text { estimates }\end{array}$ \\
\hline Non-durable goods & 25.1 & 21.3 \\
Motor vehicle manufacturing & 3.7 & 4.6 \\
Durable goods & 23.6 & 23.4 \\
Intermediate goods & 45.2 & 48.1 \\
Energy & 2.4 & 2.6 \\
\hline Total & 100 & 100 \\
\hline Number of firms & 4.283 & 2.285 \\
\hline \hline
\end{tabular}

Appendix Table A.2 : Technical and organisational innovation devices and training

\begin{tabular}{lcc}
\hline \hline & Mean & Std error \\
\hline Internet & 0.46 & $(0.59)$ \\
Introduction of network-interconnected computers (D_COMP) & 0.29 & $(0.46)$ \\
Reduction in the number of hierarchical layers (D_HIERAR) & 0.19 & $(0.39)$ \\
Increase in the amount of responsibility awarded to operators (D_RESP) & 1.02 & $(2.00)$ \\
Relative training rate of employees below 25 years old (TRAIN_1) & 0.67 & $(1.31)$ \\
Relative training rate of employees aged 25 to 44 years old (TRAIN_2) & 0.99 & $(0.50)$ \\
Relative training rate of employees aged 45 years old and above (TRAIN_3) & 0.67 & $(0.52)$ \\
\hline \hline
\end{tabular}

Sample size: 2,352 Firms. 
Appendix Table A.3 : Wage Bill Shares by Age

\begin{tabular}{|c|c|c|}
\hline & Mean & Std error \\
\hline \multicolumn{3}{|l|}{ Wage Bill Shares } \\
\hline \multicolumn{3}{|l|}{ All workers } \\
\hline 20-29 years old & 0.13 & $(0.08)$ \\
\hline $30-39$ & 0.30 & $(0.10)$ \\
\hline $40-49$ & 0.33 & $(0.09)$ \\
\hline $50-59$ & 0.24 & $(0.11)$ \\
\hline \multicolumn{3}{|l|}{ Managers } \\
\hline 20-29 years old & 0.04 & $(0.04)$ \\
\hline 30-39 & 0.12 & $(0.08)$ \\
\hline $40-49$ & 0.14 & $(0.08)$ \\
\hline $50-59$ & 0.13 & $(0.08)$ \\
\hline \multicolumn{3}{|l|}{ Clerks } \\
\hline 20-29 years old & 0.01 & $(0.02)$ \\
\hline 30-39 & 0.02 & $(0.03)$ \\
\hline $40-49$ & 0.02 & $(0.02)$ \\
\hline $50-59$ & 0.01 & $(0.02)$ \\
\hline \multicolumn{3}{|l|}{ Blue-collars } \\
\hline 20-29 years old & 0.08 & $(0.07)$ \\
\hline 30-39 & 0.16 & $(0.09)$ \\
\hline $40-49$ & 0.17 & $(0.09)$ \\
\hline $50-59$ & 0.10 & $(0.07)$ \\
\hline
\end{tabular}

Sample size: 2,352 Firms. Wage Bill Shares in 1997. 
Appendix Table A.4 : Employment Share by age

\begin{tabular}{ccc}
\hline & Mean & Std error \\
\hline $\mathbf{2 0 - 2 9}$ years old & 0.17 & $(0.09)$ \\
$\mathbf{3 0 - 3 9}$ & 0.31 & $(0.10)$ \\
$\mathbf{4 0 - 4 9}$ & 0.31 & $(0.09)$ \\
$\mathbf{5 0 - 5 9}$ & 0.21 & $(0.10)$ \\
\hline \hline
\end{tabular}

Sample size: 2,352 Firms. Employment Shares in 1997

Appendix Table A.5 : Flows by Age

\begin{tabular}{cccc}
\hline \hline & Mean & Std error \\
\hline Inflows & & & \\
& $\mathbf{2 0 - 2 9}$ years old & 0.35 & $(0.19)$ \\
& $\mathbf{3 0 - 3 9}$ & 0.14 & $(0.15)$ \\
$\mathbf{4 0 - 4 9}$ & 0.10 & $(0.14)$ \\
& $\mathbf{5 0 - 5 9}$ & 0.08 & $(0.15)$
\end{tabular}

\section{Outflows}

$\begin{array}{ccc}\mathbf{2 0 - 2 9} \text { years old } & 0.28 & (0.20) \\ \mathbf{3 0 - 3 9} & 0.14 & (0.17) \\ \mathbf{4 0 - 4 9} & 0.11 & (0.17) \\ \mathbf{5 0 - 5 9} & 0.15 & (0.18)\end{array}$

Sample size: 6824 firms * year. 